\title{
Article
}

\section{Stroke survivors' and carers' experiences of a systematic voiding programme to treat urinary incontinence after stroke}

Gibson, Josephine, Thomas, Lois Helene, Harrison, Joanna and Watkins, Caroline Leigh

Available at http://clok.uclan.ac.uk/21881/

Gibson, Josephine ORCID: 0000-0002-3051-1237, Thomas, Lois Helene ORCID: 0000-0001-5218-6546, Harrison, Joanna ORCID: 0000-0001-8963-7240 and Watkins, Caroline Leigh ORCID: 0000-0002-9403-3772 (2018) Stroke survivors' and carers' experiences of a systematic voiding programme to treat urinary incontinence after stroke. Journal of Clinical Nursing, 27 (9-10). pp. 2041-2051. ISSN 0962-1067

It is advisable to refer to the publisher's version if you intend to cite from the work. http://dx.doi.org/10.1111/jocn.14346

For more information about UCLan's research in this area go to

http://www.uclan.ac.uk/researchgroups/ and search for <name of research Group>.

For information about Research generally at UCLan please go to http://www.uclan.ac.uk/research/

All outputs in CLoK are protected by Intellectual Property Rights law, including Copyright law. Copyright, IPR and Moral Rights for the works on this site are retained by the individual authors and/or other copyright owners. Terms and conditions for use of this material are defined in the policies page. 
DR. JOSEPHINE MARY EVELYN GIBSON (Orcid ID : 0000-0002-3051-1237)

Article type : Original Article

Title:

Stroke survivors' and carers' experiences of a systematic voiding programme to treat urinary incontinence after stroke.

\title{
Running title:
}

Urinary incontinence after stroke

\author{
Authors: \\ Dr Josephine M.E. Gibson $(1,2)$ \\ Dr Lois H Thomas (3) \\ Mrs JJ Harrison (1) \\ Professor Dame Caroline Leigh Watkins (1,2) \\ On behalf of the ICONS Project Team and the ICONS Patient, Public and Carer Involvement Groups
}

\section{Affiliations:}

1. School of Nursing, University of Central Lancashire, UK

2. National Institute for Health Research Collaboration for Leadership in Applied Health Research and Care North West Coast

3. School of Health Sciences, University of Central Lancashire, UK

4.

\section{Corresponding author:}

Dr Josephine ME Gibson, School of Nursing, University of Central Lancashire, Preston, PR1 2HE. Telephone 01772 895144. Email jgibson4@uclan.ac.uk

\section{Conflicts of interest}

The authors declare that they have no conflicts of interest.

This article has been accepted for publication and undergone full peer review but has not been through the copyediting, typesetting, pagination and proofreading process, which may lead to differences between this version and the Version of Record. Please cite this article as doi: 10.1111/jocn.14346

This article is protected by copyright. All rights reserved. 


\section{Funding:}

This work was supported by a Programme Grant for Applied Health Research from the National Institute for Health Research as project number RP-PG-0707-10059. Authors 1, 2 and 4 are partfunded by the National Institute for Health Research Collaboration for Leadership in Applied Health Research and Care, North West Coast. The views and opinions expressed in this publication are those of the authors and do not necessarily reflect those of the NHS, the NIHR, CCF, NETSCC, PGFAR or the Department of Health.

\section{Stroke survivors' and carers' experiences of a systematic voiding programme to treat urinary incontinence after stroke.}

\section{Abstract}

Aims and objectives: To explore the views and experiences of stroke survivors and carers about a systematic voiding programme for post-stroke incontinence.

Background: Urinary incontinence after stroke is common and associated with poorer functional outcome. Structured assessment and management are potentially effective interventions but it is important that there is a good understanding of stroke survivors' and carers' views of their acceptability and implementation.

Design: Qualitative study within a feasibility trial.

Methods: 16 participants (12 stroke survivors, 4 carers) were interviewed using a structured schedule shortly before discharge from one of six inpatient stroke units across six hospitals. Interviews were audiorecorded, transcribed verbatim, and thematic analysis was conducted.

Findings: Participants included seven male and five female stroke survivors (mean age 76 years), and four female carers (two wives, two daughters). Themes relating to the preliminary (assessment) phase of the programme were: physical impact, psychological impact, beliefs about incontinence, and the assessment process itself. Main themes relating to the implementation of the programme included: Timed voiding decisions, adapting the programme or the timed voiding schedule, and urinary incontinence management techniques. Participants felt that the programme helped them to re-establish a regular pattern of micturition and to regain autonomy.

Conclusions: The effectiveness of a systematic voiding programme may partly lie in its educational component, challenging patients' and carers' assumptions that post-stroke incontinence is inevitable. Individual adaptation of the programme, and the ability to incorporate it alongside other aspects of care, are likely to be key factors influencing implementation.

Relevance to clinical practice: Urinary incontinence is common after stroke. In order to maximise benefits from a systematic voiding programme, nurses should support stroke survivors to overturn erroneous beliefs, to participate in tailoring of the programme, and in self-management where appropriate.

This article is protected by copyright. All rights reserved. 


\section{What does this paper contribute to the wider global clinical community?}

- Nursing staff should support self-assessment and shared decision-making where possible, as these appear to be valued by people with post-stroke incontinence.

- A systematic voiding programme requires careful monitoring of progress, and integration within each stroke survivor's rehabilitation timetable.

- The benefit of a systematic voiding programme may be enhanced by enabling and encouraging its adaptation by stroke survivors and carers.

Keywords. Adult Nursing; Incontinence; Stroke; Qualitative Study; Patients' Experience

\section{Introduction}

Urinary incontinence (UI) is a common problem after stroke (Nakayama at al.,1997; KolominskyRabas et al., 2003; Williams et al., 2012; Tuong et al., 2016), affecting at least $50 \%$ of stroke survivors. Although UI sometimes resolves rapidly and spontaneously, for many people it becomes a persistent problem, with up to a third of stroke survivors experiencing some degree of $\mathrm{UI}$ at six or twelve months (Nakayama et al., 1997; Williams et al., 2012; Mehdi et al., 2013). Ul is a strong predictor of mortality risk (John et al., 2016) and poor functional outcome after stroke (Patel et al., 2001; Meijer 2003; Mehdi et al., 2013). It is associated with higher rates of psychological problems such as depression and loss of confidence (Brittain, 1998; Limamapi et al., 2017), and can result in reduced independence, caregiver burden (Rigby et al., 2009) and the need for institutional living (Patel et al., 2001; Kolominsky-Rabas et al 2003; Dutta et al., 2017). While the type and severity of UI varies, the most common symptoms (alone or in combination) are urinary frequency, urgency (a sudden compelling desire to urinate), and stress incontinence (involuntary leakage) (Marinkovic 2001). Functional UI can also arise from post-stroke sequelae such as, for example, motor impairment, depression and aphasia, which lead to difficulties with mobilising to the toilet, with manipulating clothing, or with communicating the need for toileting to a carer (Brittain, 1998; Brittain et al., 1999).

UI post-stroke has been identified as debasing (Kvigne and Kirkevold, 2003), embarrassing and depressing (Pilcher and MacArthur, 2012), and shameful (Kohler et al, 2017) by stroke survivors. It has adverse impacts on daily life and psychological wellbeing (White et al., 2014; Arkan et al, 2018), and places a heavy burden on both stroke survivors (Kohler et al, 2017) and their carers (Brittain and Shaw, 2007; Tseng et al., 2015; Arkan et al., 2018). Ul post-stroke is recognised as one of the top 10 priorities for stroke nursing research (Rowat et al, 2016). Despite a number of trials of diverse interventions for post-stroke $\mathrm{UI}$, including behavioural, professional input, complementary, hormonal and pharmacological therapies (Tuong et al., 2016), a Cochrane review has identified that

This article is protected by copyright. All rights reserved. 
there are no clearly effective treatments for post-stroke UI (Thomas et al 2009; Tibaek et al., 2015), and its management in clinical practice is suboptimal (Mehdi et al., 2013). However, professional input through structured assessment and management of care, and specialist continence nursing both show promise as methods to reduce urinary incontinence and related symptoms after stroke (Thomas et al., 2009). If these potentially effective complex interventions are to be developed and tested further, it is important that there is a good understanding of stroke survivors' and carers' views of their acceptability and how they might best be implemented. A recent review identified several studies that evaluated barriers and enablers of the uptake of complex interventions for $\mathrm{UI}$ from the perspectives of people (mainly women) with UI arising from various causes, but none of these studies examined the perspectives of stroke survivors with UI or their carers, and many had significant methodological weaknesses (French et al., 2017).

A multicentre exploratory cluster randomised controlled trial of a systematic voiding programme (SVP) for post-stroke Ul reported that it is feasible to conduct a full cluster RCT and provided some evidence of a potential reduction in the odds of specific types of incontinence (Thomas et al 2014). The SVP in this trial was a multistage programme, comprising assessment (including a comprehensive continence assessment), individualised conservative interventions tailored to the physical and cognitive capabilities of each patient, and weekly review. As part of a process evaluation using Grant's framework (2013) of this SVP, a qualitative study was conducted with stroke survivors and carers who had used the SVP. The aim of the study was to explore the views and experiences of stroke survivors and carers about the implementation of a systematic voiding programme (SVP) after stroke.

\section{Method}

The study formed part of a process evaluation, using Grant's framework (2013), of a feasibility cluster RCT (Thomas et al., 2014). The study design also drew on principles of phenomenology to explore people's lived experiences of post-stroke UI and of undertaking the SVP.

The systematic voiding programme entailed two phases: an initial assessment phase and a core phase. The initial assessment phase comprised a three day bladder diary and a comprehensive nursing assessment of continence for those who were not continent, including history taking and physical examination; urine dipstick examination and bacteriological testing if needed; an estimation of post-void residual urine volume (if indicated); and an identification of the type of incontinence. Nursing and medical staff then recommended an appropriate individualised treatment plan for the

This article is protected by copyright. All rights reserved. 
core phase. The core phase comprised an initial management phase (days 3-7) and an ongoing management and reassessment phase (day 7 onwards). It included pelvic floor muscle training, bladder training including urge suppression, distraction, and an individualised voiding schedule, an education programme, and a patient-held voiding diary. People with cognitive impairment undertook a prompted voiding programme and participated in the education programme and diarykeeping to the extent that they were able.

All stroke survivors and carers in any of the trial intervention sites throughout England and Wales were eligible to take part in the interviews. Inclusion criteria were: stroke survivors admitted to study sites, aged 18 or over (no upper age limit); experiencing UI, defined as 'involuntary loss of urine' (Abrams, Cardozo and Fall, 2002); conscious; medically stable (as judged by the clinical team); and either having incontinence (stress $\mathrm{UI}$, urge $\mathrm{UI}$, mixed $\mathrm{UI}$ or functional UI), or catheterised in the acute phase of the stroke. Because the presence of communication and cognitive problems might affect people's experience of UI and of the SVP, we sought to include people both with and without post-stroke aphasia or cognitive impairment. Participants who had UI before the index stroke were included. Participants who were catheterised were recruited; if the catheter was removed, they were assessed as per protocol and began the SVP if they were still incontinent. Exclusion criteria were: pre-existing long-term catheter in situ; routine self-catheterisation prior to stroke; stroke survivors who declined to take part; stroke survivors who were unable to give informed consent at the time of recruitment and for whom their consultee did not agree that the stroke survivor would wish to be included.

Interviews took place in a quiet private room within each of the six participating stroke units. Stroke survivors who were taking part were invited to have a carer participating in the interview, or present for support if they wished. Interviews were conducted by experienced health care researchers (authors 2 and 3 ) or local research nurses. None of the interviewers had clinical responsibility for these patients. Interviews used a structured interview schedule which was developed by the research team with members of the study's Patient, Carer and Public involvement group. The schedule included largely open-ended questions, which was developed to reflect the elements of the SVP (see Appendix 1). Interviews were digitally audio-recorded and fully transcribed, unless the participants declined permission to record, in which case the researcher instead made contemporaneous notes of the discussion.

The analysis of transcripts or contemporaneous notes utilised a thematic approach largely based on Braun and Clarke's (2006) phases of analysis. A deductive approach was taken where emerging themes were mapped onto the SVP and the emerging logic model for the feasibility trial. A sample of

This article is protected by copyright. All rights reserved. 
the coding was verified by another researcher (author 2). The overall analysis was discussed and refined with all authors, members of the trial steering group and the Patient and Public Involvement Group.

Ethical and data protection issues:

Local Research Ethical Approval was granted by Bolton Research Ethics Committee (09/H1009/15). Approval was also obtained from the host academic institution. Participants were asked at the time of recruitment to the trial if they would consider taking part in a research interview at a later date. If the stroke survivor initially lacked capacity to consent, a consultee (usually a close family member) was asked to give assent. Written informed consent or assent was obtained from all participants shortly before each interview. The voicefile for each interview was uploaded as soon as possible onto a secure password-protected area on the university mainframe and the original recording was then erased. All identifying details were redacted from the final transcriptions. The COREQ guidelines were consulted in reporting of the study.

\section{Findings}

\section{Stroke survivor characteristics}

Data collection took place from June 2011 to June 2012. Twelve interviews were undertaken with a total of sixteen participants (twelve stroke survivors and four carers) from across six study sites. Seven patients were male, five were female. The mean age was 76 years (range $60-88$ years) and all were of white British ethnicity. Half had pre-stroke UI. Stroke survivor characteristics are shown in Table 1.

Eight stroke survivors were interviewed alone, two with their wife, and two with their daughter. Interviews lasted from 13 to 39 minutes (mean 22 minutes).

Most participants $(n=9)$ had no communication problem or cognitive impairment. Two had aphasia; another was noted to have apparent cognitive problems during the interview. Two interviews were not digitally recorded: one (A2) due to a noisy environment, and one (A4) at the request of the participant, who had post-stroke aphasia. (see Table 1 for summary participant characteristics.)

This article is protected by copyright. All rights reserved. 


\section{Themes identified}

Themes from an initial thematic analysis were integrated with an emerging logic model for the trial which included two main phases relating to this analysis: preliminary and core activity. The themes are outlined in Figure 1.

\section{PRELIMINARY PHASE: MAKING A DECISION ABOUT URINARY INCONTINENCE}

Participants' engagement in the programme in the preliminary assessment phase was rooted in three key aspects of their experience of UI: its physical impact, psychological/social impact, and their prior beliefs about UI. The physical experience of UI post-stroke was intimately related to psychological distress and feelings of a lack of control and self-determination about one's life. This was compounded by prior beliefs about the inevitability of post-stroke UI. Engagement in the formal assessment process of the SVP was felt to be useful to foster a sense of acknowledgement, dialogue and self-management which began to counter these impacts, in addition to its practical purpose of clinical assessment.

\section{1a) Physical impact of incontinence}

Participants talked about the physical impact of UI in terms of lack of control, or lack of awareness:

A1: 'Well I used to feel like I wanted to go and I needed to go, (but) before they (nurses) could come to me it (urine) came away from me, so there wasn't much I could do about that...I tried to control it but I couldn't do.'

Participants also vividly described the physically unpleasant effects of UI, notably wet bedding or wet clothing. Skin discomfort and possible effects on skin integrity were also mentioned:

A3: 'Lying in it is just absolutely dreadful, I got so sore ... my skin feels as if it's burning, which meant when I went for a shower I had to be very careful, in fact on one or two occasions I thought I wonder if I've got scalded with the shower.'

This article is protected by copyright. All rights reserved. 


\section{1b) Psychological and social impact of incontinence}

There were a variety of negative emotions described relating to the experience of UI. These included worry, frustration, being depressed or 'down', and embarrassment:

B6: 'the more you do it (have incontinence episodes) the more frustrated you get... and the more depressed you get.'

E8: 'it can get you down ... it feels like it's ... took part of your life, you know what I mean.'

Although interviews took place prior to discharge from hospital, there was concern about the potential impact of UI on their partner and on their intimate relationships:

A3: 'I'd be very, very worried ... ruining a good bed, and ... wetting a nice partner.'

\section{1c) Beliefs about incontinence and stroke}

Before participating in the SVP, some participants had held the belief that UI was an inevitable consequence of stroke. Combined with the physical sensation of lack of control over bladder function, this led to feelings of powerlessness, loss of self-agency, and a belief that little or nothing could be done to address the condition:

B7: 'I just felt it was just par for the course really ... I suppose so many people do have incontinence problems when they've had a stroke.'

However, there was also an opposing view held by some participants who had experienced prestroke UI or urinary frequency: they felt that their symptoms had improved since the stroke:

H9: 'I think it's just a natural effect of the stroke I think, I have heard it said that people who have had a stroke often urinate less frequently afterwards.'

\section{1d) Assessment of incontinence}

Many stroke survivors did not remember much about the initial assessment period of the SVP, perhaps because it had taken place early after the stroke when they were still acutely unwell. However, the nursing assessment process was seen to enable the stroke survivor to acknowledge the problem and the need for intervention. This acknowledgement was essential for engagement in the programme:

This article is protected by copyright. All rights reserved. 
L11: 'Your programme gets the person to admit they've got incontinence, and once they admit they've got it and that they need help, that's the big thing.'

The benefit of staff engaging in discussion of $\mathrm{Ul}$ as part of the assessment process also helped to build a therapeutic relationship:

A3: 'I think it's probably helped a lot, with somebody else taking an interest.'

The importance of self-management was central even in this early phase. Some stroke survivors and carers engaged actively in the practical processes of assessment:

L11: 'In the first week we wrote it in the booklet and we kept a note of things.' (daughter of stroke survivor)

There was, however, also some evidence of misunderstanding in the assessment phase regarding the diagnosis of UI. Some stroke survivors or staff did not appear to understand that functional UI alone (where $\mathrm{UI}$ is attributable solely to non-urinary causes, such as difficulty with mobilising to the toilet in time or in manipulating clothing) was a valid reason for commencing the SVP. This may have also reflected a misunderstanding of the programme itself, since all participants were in fact on it:

B6: 'Once they realised that it weren't a 'bladder out of control', then they chose not to put me on the programme.'

\section{CORE PHASE: IMPLEMENTING THE PROGRAMME}

This phase was characterised by adaptation of the programme, and further engagement in selfmanagement via its implementation and adaptation. Participants also discussed the importance of individualisation which was inherent throughout the programme.

\section{a) Timed voiding decisions}

This theme included the planning and implementation of the individual programme with the stroke survivor; setting the timing interval for individualised toileting was a key element. There was an element of trial and error in selecting the appropriate timed voiding interval:

A1: 'The two-and-a-half hour (interval) was, I couldn't make it, but the two hour (interval) I could do it.'

This article is protected by copyright. All rights reserved. 
It was also recognised that nursing staff had to devote considerable time and effort to the timed voiding programme, and had to make time to do this in the midst of multiple other activities:

B5: 'So the fact that the nurses consciously set a time aside and go and ask and do it regularly.'

Both nurses and stroke survivors were 'busy', however. Participants recognised that it was sometimes challenging for nursing staff to co-ordinate timed voiding with other activities in the stroke survivor's day, such as therapy sessions or off-ward visits for investigations or interventions:

L11: 'I was surprised the nurses would think about it often enough, 'cos you're out and about all over the place (as a stroke survivor undergoing rehabilitation).'

\section{b) Adapting the programme or the timed voiding schedule}

This theme included evaluation of progress on the programme and its subsequent adaptation. It included the formal evaluation and adaptation which was conducted with or by nursing staff, but stroke survivors themselves also adapted the programme independently to suit their needs. Participants identified that the SVP was not a quick or easy solution to UI. They realised that although setbacks might be disheartening, it was nonetheless important to maintain their internal motivation during the programme. This was in direct opposition to the beliefs about the inevitability of post-stroke Ul that they previously held: far from feeling that it was 'par for the course', they now understood that it was vital to maintain a positive attitude:

A1: 'If you have an accident (episode of incontinence), fair enough it can't be helped, but you don't give up on yourself.'

Particularly for people who needed practical assistance with toileting, timing was crucial. If they requested help too early, they would find that they were unable to urinate when the opportunity was provided; if too late, they might have an episode of UI. As well as the ability to recognise the urge to urinate, they needed to develop detailed knowledge of how quickly the nursing staff were likely to respond, which might vary from shift to shift, at different times of day or on different days of the week, depending on the ward routine. Thus, in addition to self-management of their UI, the participants described using this acquired knowledge to 'manage' the nursing staff in order to get the assistance they needed in a timely fashion:

A3: 'I'd normally press the buzzer just in time - not too early because nothing might happen - so I time it as best I can.'

This article is protected by copyright. All rights reserved. 
As with the initial assessment, some participants took an active role in self-monitoring throughout the programme. However, the 'official' trial paperwork was found to be somewhat cumbersome. Ownership of their own progress monitoring was demonstrated by those who adapted the process for their own needs:

L11: 'I found a notepad was easier 'cos it's a smaller piece of paper and you can just flick through the days.'

\section{c) UI management techniques}

In this theme, participants evaluated the SVP as a whole and the specific techniques that they used. Distraction techniques were found to be of limited use: exercises such as 'counting backwards from 100 in sevens', as suggested in the programme, were not well received. It was felt that such measures were challenging even as a stand-alone exercise, and were very hard to achieve in the context of bladder training:

L11: 'It was so hard to do, it was one of the memory tests they gave him as well counting in sevens ... I couldn't, couldn't do it.' (daughter of stroke survivor)

The prompted voiding programme was, however, found to be useful in re-establishing a regular pattern of micturition in order to 'get back in the habit':

A4: 'It meant you got very good attention, frequent reminders, that you got back into the habit of going.'

Participants also found that the prompted voiding programme enabled them to gradually take control of their own toileting:

B5: 'They asked you if you wanted the bedpan, and now you're more ringing for it yourself.' (Daughter of stroke survivor)

Prompted voiding was found to be especially useful for people with post-stroke aphasia, who might have otherwise had difficulty in formulating and expressing a request for toileting. The regular regime made it comparatively easy for them to respond to a staff query about their toileting needs:

B5: 'It might have taken longer to know what she wanted to say; it is sometimes difficult to make us understand.' (Daughter of stroke survivor)

This article is protected by copyright. All rights reserved. 


\section{Discussion}

This study has identified that stroke survivors' and carers' experiences of undertaking a SVP for poststroke $\mathrm{UI}$ are grounded in their experience of, and beliefs about, $\mathrm{UI}$ itself. $\mathrm{UI}$ is physically and psychologically unpleasant for those that experience it, but is sometimes held to be inevitable after stroke. Although the primary purposes of the preliminary phase of the SVP are to identify underlying causes of incontinence and to make decisions about management, the assessment process also acts as a signifier to stroke survivors and carers that nurses and other health professionals take $\mathrm{UI}$ seriously, as a way of opening up conversation, and of addressing erroneous beliefs about the inevitability of UI.

In the core phase of the SVP, stroke survivors engage actively in the programme, by adapting it to their needs and according to their progress, particularly in relation to modifying timed voiding intervals and in self-monitoring. This may represent a gradual retaking of control in which they engage in in self-management (with support), and this in itself may benefit confidence and recovery.

This is one of the first studies to examine the perspectives of carers as well as those of people with post-stroke UI (from any underlying cause), and also to endeavour to include people with cognitive or communication impairment. The study is also novel in including a majority of men, although the sample size was too small to enable the development of any specific themes relating to men's and women's perspectives of post-stroke UI and of the SVP. All the interviews were conducted by female researchers. It is possible that this may have affected participants' responses on this sensitive topic, particularly with male participants. It was, unfortunately, not possible in this study to offer participants a choice of a male or female interviewer. Data collection was limited to those who had actually used the SVP during their stay on a stroke unit. It is possible that people in sites allocated to 'Usual Care' may have reported similar experiences to the sample interviewed, but there is no data to support or refute this. Interviews were undertaken in the hospital setting shortly before discharge, and we were unable to explore participants' experiences of the long-term impact of the programme post-discharge.

The psychological and physical impact of post-stroke UI on stroke survivors has been explored in previous studies (Pilcher et al., 2012; White et al., 2014; Kohler et al., 2017; Limampai et al., 2017; Arkan et al., 2018). Ul is associated with post-stroke depression (Pilcher et al., 2012; Limampai et al., 2017), is seen as embarrassing (Pilcher et al., 2012), shameful and not to be discussed (Kohler et al., 2017), and is something that is never mentioned by health professionals (White et al., 2014).

Participants in this study spoke of feeling 'depressed' or 'down' about UI even in the relatively short

This article is protected by copyright. All rights reserved. 
time period of their inpatient stay, but also felt that a key task for nurses and other health professionals in supporting people with UI early after stroke was to 'get the person to admit that they've got incontinence', which necessitated overcoming this shame and silence. Although the impact of post-stroke UI on carers after discharge from hospital has been studied (Rigby et al., 2009; Tseng et al., 2015; Arkan et al., 2018), no previous research has examined the involvement of carers in in-patient continence care or in the use of a SVP. This study also adds to previous research on the development of self-management strategies by people with post-stroke $\mathrm{UI}$, both in the inpatient setting (Kohler et al., 2017) and after discharge home (White et al., 2014), and the need, which is recognised by healthcare professionals, for stroke survivors to be offered a proactive individualised approach (Pilcher et al., 2012). This is, however, the first study to identify that a stroke survivor's process of self-management may also entail the acquisition of knowledge during their inpatient stay which enables them to 'manage' the nursing staff in order to obtain timely assistance. Since this study was conducted, a further qualitative study of a complex intervention for post-stroke UI has also been reported (Brady et al., 2016). The major themes that they identified from stroke survivors' perspectives were: challenges in communicating about continence, mixed perceptions of continence care, ambiguity of focus between mobility and continence issues, and inconsistent involvement in continence care decision making. There is some resonance with the findings of the present study, in particular the difficulty in balancing continence care with other rehabilitation activities. However, there are some other divergent findings. In the present study, the SVP was felt to be a valuable tool for opening up conversations about $\mathrm{UI}$, and participants did not express any overtly negative opinions about continence care, instead expressing views that staff were very supportive, despite their heavy workloads. None of the participants expressed a view that they were insufficiently involved in decision making, although this was not something that was specifically included in the interview schedule, and the SVP was felt to be a valuable tool in self-management of UI.

Systematic voiding programmes for post-stroke UI have not yet been fully evaluated in a definitive randomised controlled trial. Future trials (in post-stroke and other UI) may need to be designed in such a way as to enable, and allow for, adaptation of the programme by participants. However, methods need to be devised to ensure and monitor treatment fidelity to the principles of the SVP, which might potentially be compromised by flexible approaches to the practical implementation of the programme.

This article is protected by copyright. All rights reserved. 
It was apparent that some participants with functional UI held a view that this was not 'true' $\mathrm{UI}$, and were therefore unsure why they had been included in the programme. Educational materials for stroke survivors and carers who are participating in future trials may need modification to address this misconception.

\section{Conclusion}

The development of a systematic voiding programme for the treatment of post-stroke $\mathrm{UI}$ is valued by patients and carers. The utility of the programme may be related partly to its educational value, its potential to overturn assumptions about the inevitability of the condition, and to the adaptation of peripheral components. Nurses working with stroke survivors need to support self-assessment and shared decision-making where possible, close monitoring of progress, and individual adaptation of the programme where needed.

\section{Relevance to clinical practice}

Although the findings are based on only a small sample size, some tentative suggestions can be made for nursing care in this area.

In the assessment phase of UI, staff need to pay frequent attention to comfort and hygiene, acknowledge the physical and psychological burden of $\mathrm{UI}$, adopt a non-judgemental approach, and challenge any erroneous beliefs the stroke survivor and carer may have about UI post-stroke. Assessment and planning should include self-assessment and shared decision-making where possible, as these appear to be valued by stroke survivors.

During the use of a systematic voiding programme, the SVP needs to be a nursing priority, with careful monitoring of progress and consideration of how the SVP dovetails with the stroke survivor's overall rehabilitation timetable. Stroke survivors appear to become expert in gauging the nurses' workload and in 'managing' their condition accordingly, by optimising the timing of their requests for assistance. It is none the less important that nurses convey an attitude that $\mathrm{UI}$ management is a high-priority nursing duty, via careful assessment, planning, delivery and evaluation of UI care. This may help to counteract the view that $\mathrm{UI}$ is inevitable and untreatable, will help to maintain dignity and comfort, and may improve the chance of successful management of UI. Possible adaptation of the SVP for use by individual stroke survivors may include maintaining a positive approach, simplification to enable self-monitoring e.g. in aphasia, and enabling the stroke survivor to gradually

This article is protected by copyright. All rights reserved. 
take control of the management of their UI. This approach would be consistent with the principles of implementation science (Damschroder et al 2009), where 'core components' (e.g. the voiding interval) should not be altered, in contrast to an 'adaptable periphery' (e.g. patient self-monitoring). While some broad principles and strategies are known to be helpful, it is important to enable, and even perhaps encourage, adaptation of the programme.

\section{References}

Abrams P, Cardozo L, Fall M (2002) The standardisation of terminology of lower urinary tract function: report from the Standardisation Sub-Committee of the International Continence Society. Neurourol Urodyn 2002, 21: 167-178. http://dx.doi.org/10.1016/S0090-4295(02)02243-4

Arkan G, Beser A, Ozturk V (2018) Experiences Related to Urinary Incontinence of Stroke Patients: A Qualitative Descriptive Study. Journal of Neuroscience Nursing. 50(1):42-47.

Brady MC, Jamieson K, Bugge C, Hagen S, McClurg D, Chalmers C, Langhorne P (2016) Caring for continence in stroke care settings: a qualitative study of patients' and staff perspectives on the implementation of a new continence care intervention. Clinical Rehabilitation Vol 30, Issue 5, pp. 481-494. https://doi.org/10.1177/0269215515589331

Braun V, Clarke V (2006) Using thematic analysis in psychology. Qualitative Research in Psychology Vol. 3, (2) 77-101

Brittain K and Shaw C (2007) The social consequences of living with and dealing with incontinence a carers' perspective. Social Science and Medicine 65 (6) 1274-83.

https://doi.org/10.1016/j.socscimed.2007.04.002

Brittain KR, Peet SM, Castleden MD. (1998) Stroke and incontinence. Stroke; 29:524-8. https://doi.org/10.1161/01.STR.29.2.524 Can J Urol. 2016 Jun;23(3):8265-70.

Brittain KR, Peet SM, Potter JF, Castleden CM. (1999) Prevalence and management of urinary incontinence in stroke survivors. Age Ageing 28(6):509-511

Damschroder L, Aron DC, Keith RE, Kirsh SR, Alexander JA, Lowery JC (2009). Fostering implementation of health services research findings into practice: a consolidated framework for advancing implementation science. Implementation Science 4:50 https://doi.org/10.1186/17485908-4-50

This article is protected by copyright. All rights reserved. 
Dutta D, Thornton D, Bowen E. (2017) Using population-based routinely collected data from the Sentinel Stroke National Audit Programme to investigate factors associated with discharge to care home after rehabilitation. Clinical Rehabilitation 1-11 DOI: 10.1177/0269215517748715

French B, Thomas LH, Harrison J, Coupe J, Roe B, Booth J, Cheater FM, Leathley MJ, Watkins CL, HaySmith J; ICONS Project Team and the ICONS Patient, Public and Carer Groups. (2017)Client and clinical staff perceptions of barriers to and enablers of the uptake and delivery of behavioural interventions for urinary incontinence: qualitative evidence synthesis. J Adv Nurs. 73(1):21-38. doi: 10.1111/jan.13083.

Grant A, Treweek S, Dreischulte T, Foy R, and Guthrie B (2013) Process evaluations for clusterrandomised trials of complex interventions: a proposed framework for design and reporting. Trials; 14: 15- http://dx.doi.org/10.1186/1745-6215-14-15

John, G, Bardinic C, Mégevand, P, Combescure C, Dällenbach P (2016) Urinary incontinence as a predictor of death after new-onset stroke: a meta-analysis. European Journal of Neurology 2016, 23: 1548-1555 doi:10.1111/ene.13077

Kohler M, Mayer H, Kesselring J, Saxer S (2107) (Can) Not talk about it - Urinary incontinence from the point of view of stroke survivors: a qualitative study. Scand J Caring Sci; DOI: 10.1111/scs.12471 Kolominsky-Rabas, Hilz PL, Neundorfer MJ, Bernhard-Heuschmann, PU (2003) Impact of urinary incontinence after stroke: Results from a prospective population-based stroke register. Neurourology and Urodynamics. 22 (4) 322-327. DOI: 10.1002/nau.10114

Kvigne K and Kirkevold M (2003) Living with bodily strangeness: Women's experiences of their changing and unpredictable body following a stroke. Qualitative Health Research 13 (9) 1291- 1310. DOI: $10.1177 / 1049732303257224$

Limampai P, Wongsrithep W, Kuptniratsaikul V (2017) Depression after stroke at 12-month followup: a multicenter study. International Journal of Neuroscience Vol. 127 , Iss. 10,2017

Marinkovic S, Badlani G (2001). Voiding and sexual dysfunction after cerebrovascular accidents. Journal of Urology; 165 (2):359-70 doi.org/10.1097/00005392-200102000-00003

Mehdi Z, Birns J, Bhalla A. (2013) Post-stroke urinary incontinence. Int J Clin Pract, 67, 11, 11281137. doi: $10.1111 /$ ijcp.12183

Meijer R, Ihnenfeldt DS, de Groot IJM, van Limbeek J, Vermeulen M, de Haan RJ (2003) Prognostic factors for ambulation and activities of daily living in the subacute phase after stroke. A systematic

This article is protected by copyright. All rights reserved. 
review of the literature. Clinical Rehabilitation 2003;17(2):119-29. DOI:

$10.1191 / 0269215503 \mathrm{cr} 5850 a$

Nakayama H, Jørgensen HS, Pedersen PM, Raaschou HO, Olsen TS (1997) Prevalence and risk factors of incontinence after stroke. the Copenhagen stroke study. Stroke. 28:58-62

https://doi.org/10.1161/01.STR.28.1.58

Patel M, Coshall C, Rudd AG, Wolfe CDA (2001) Natural history and effects on 2-year outcomes of urinary incontinence after stroke. Stroke. 32:122-127

Pilcher M, MacArthur J. Patient experiences of bladder problems following stroke. Nurs Stand. 2012 May 9-15;26(36):39-46.

Rigby H, Gubitz G, Eskes G, Reidy Y, Christian C, Grover V, Phillips S. (2009) Caring for stroke survivors: baseline and 1-year determinants of caregiver burden. Int J Stroke. 2009 Jun;4(3):152-8. doi: 10.1111/j.1747-4949.2009.00287.x.

Rowat A, Pollock A, St George B, Cowey E, Booth J, Lawrence M; Scottish Stroke Nurses Forum (SSNF) (2016) Top 10 research priorities relating to stroke nursing: a rigorous approach to establish a national nurse-led research agenda. J Adv Nurs 72(11):2831-2843. doi: 10.1111/jan.13048.

Thomas LH, Cross S, Barrett J, French B, Leathley M, Sutton CJ, Watkins C (2008) Treatment of urinary incontinence after stroke in adults. Cochrane Database of Systematic Reviews Issue 1. Art. No.: CD004462. DOI: 10.1002/14651858.CD004462.pub3.

Thomas LH, Watkins CL, Sutton CJ, Forshaw D, Leathley MJ, French B, Burton CR, Cheater F, Roe B, Britt D, Booth J, McColl E and The ICONS Project Team and the ICONS Patient, Public and Carer Involvement Groups (2014) Identifying continence options after stroke (ICONS): a cluster randomised controlled feasibility trial. Trials 15:509 doi: 10.1186/1745-6215-15-509

Tibaek S, Gard G, Dehlendorff C, Iversen HK, Biering-Soerensen F, Jensen R (2015) Is pelvic floor muscle training effective for men with poststroke lower urinary tract symptoms? A single-blinded randomized, controlled trial. American Journal of Men's Health 1-12. DOI:

$10.1177 / 1557988315610816$

Tseng CN, Huang GS, Yu PJ, Lou MF (2015) A qualitative study of family caregiver experiences of managing incontinence in stroke survivors. PLoS One. 2015 Jun 12;10(6):e0129540. doi: 10.1371/journal.pone.0129540.

This article is protected by copyright. All rights reserved. 
Tuong NE, Klausner AP, Hampton LJ. A review of post-stroke urinary incontinence. Can J Urol. 2016 Jun;23(3):8265-70.

White JH, Patterson K, Jordan LA, Magin P, Attia J, Sturm JW. (2014) The experience of urinary incontinence in stroke survivors: A follow-up qualitative study. Canadian Journal of Occupational Therapy Vol. 81(2) 124-134 DOI: 10.1177/0008417414527257

Williams MP, Srikanth V, Bird M, Thrift AG (2012) Urinary symptoms and natural history of urinary continence after first-ever stroke-a longitudinal population-based study. Age Ageing 41 (3): 371376. doi: 10.1093/ageing/afs009

This article is protected by copyright. All rights reserved. 
Table 1: Participant characteristics. Letters denote different trial sites.

\begin{tabular}{|c|c|c|c|c|c|c|}
\hline Participant & Age & Gender & $\begin{array}{l}\text { Pre- } \\
\text { stroke } \\
\text { UI }\end{array}$ & $\begin{array}{l}\text { Type of UI } \\
\text { at trial } \\
\text { recruitment }\end{array}$ & $\begin{array}{l}\text { Interview } \\
\text { with }\end{array}$ & $\begin{array}{l}\text { Communication or } \\
\text { cognitive } \\
\text { impairment }\end{array}$ \\
\hline A1 & 73 & Female & Yes & Urge & $\begin{array}{l}\text { Stroke } \\
\text { survivor }\end{array}$ & None \\
\hline $\mathrm{A} 2$ & 80 & Female & No & Functional & $\begin{array}{l}\text { Stroke } \\
\text { survivor }\end{array}$ & $\begin{array}{l}\text { Mild cognitive } \\
\text { impairment }\end{array}$ \\
\hline A3 & 74 & Male & $\begin{array}{l}\text { Not } \\
\text { known }\end{array}$ & Catheterised & $\begin{array}{l}\text { Stroke } \\
\text { survivor }\end{array}$ & None \\
\hline A4 & 79 & Male & No & Mixed & $\begin{array}{l}\text { Stroke } \\
\text { survivor and } \\
\text { wife }\end{array}$ & Aphasia \\
\hline B5 & 88 & Female & Yes & Mixed & $\begin{array}{l}\text { Stroke } \\
\text { survivor and } \\
\text { daughter }\end{array}$ & Aphasia \\
\hline B6 & 68 & Male & No & Functional & $\begin{array}{l}\text { Stroke } \\
\text { survivor and } \\
\text { wife }\end{array}$ & None \\
\hline B7 & 73 & Female & Yes & Functional & $\begin{array}{l}\text { Stroke } \\
\text { survivor }\end{array}$ & None \\
\hline E8 & 60 & Male & Yes & Mixed & $\begin{array}{l}\text { Stroke } \\
\text { survivor }\end{array}$ & None \\
\hline H9 & 85 & Male & $\begin{array}{l}\text { Not } \\
\text { known }\end{array}$ & Mixed & $\begin{array}{l}\text { Stroke } \\
\text { survivor }\end{array}$ & None \\
\hline K10 & 84 & Male & No & Mixed & $\begin{array}{l}\text { Stroke } \\
\text { survivor }\end{array}$ & None \\
\hline L11 & 69 & Male & Yes & Urge & $\begin{array}{l}\text { Stroke } \\
\text { survivor and } \\
\text { daughter }\end{array}$ & None \\
\hline L12 & 80 & Female & Yes & Mixed & $\begin{array}{l}\text { Stroke } \\
\text { survivor }\end{array}$ & None \\
\hline
\end{tabular}

This article is protected by copyright. All rights reserved. 
Figure 1. Themes identified by stroke survivors and carers within preliminary and core phases of a systematic voiding programme for post stroke urinary incontinence.

1. PRELIMINARY PHASE MAKING A DECISION

a) Physical impact of UI

b) Psychological impact of UI

c) Beliefs about UI

d) Assessment of UI
2. CORE PHASE - IMPLEMENTING THE PROGRAMME

a) Timed voiding decisions: Trial and error; Nursing time and effort; Conflict with other activities

b) Adapting the programme or the time voiding schedule: Keeping motivated; Managing timing; Selfmonitoring

c) UI management techniques: Distraction; Getting back in the habit

This article is protected by copyright. All rights reserved. 


\section{Appendix: Semistructured interview schedule.}

\section{Overview of interview - consent, guidance and thanks}

Consent will already have been gained for participation in the study. So prior to the interview, the researcher will check (a) that the person is still willing to participate, (b) that they understand the interview, and (c) check to determine if the person is still willing to be audio-recorded. Once the researcher is assured that the person is informed and still willing to participate, the semi-structured interview would commence.

These questions aim to be prompts to allow the researchers to broadly cover the same ground with each person but the schedule will not necessarily be rigidly adhered to.

If the person has already addressed a topic, then a question covering that topic later in the interview may well be skipped (unless the researcher feels that asking it will result in an additional perspective).

If a person becomes tired or indicates they wish to terminate the interview, then the remaining questions will not be asked. If the person would like to continue with the interview at a later date, either face-to-face or over phone, then this could be arranged at a mutually convenient time.

If a person chooses not to answer a question or appears reluctant to answer a question or provide more detail, then they will not be pressed to do so.

The person will then be thanked for agreeing to take part in the interview and told that we think that their views are really important to us and that they should feel free to be frank about the things they tell us and that we will assure their anonymity and confidentiality.

The questions have been grouped to help focus the person's thoughts about each component of the package with some introductory questions to help engage and settle the person into the interview. Before the start of the conversational aspect of the interview some key data will be collected.

Please note: the researcher should establish early on the preferred language to use in relation to terms such as voiding - for example, if the carer prefers to talk about emptying their bladder or passing water or having a wee etc and then use this language as appropriate. If the term 'going to the toilet' is used, the researcher should be sure that the participant does mean voiding rather than defecating and they should be aware that 'going to the toilet' is not necessarily the same as going to the toilet AND voiding.

\section{Section 1: Introductory questions}

These first questions are about how you feel about your urinary symptoms

1. Can you tell me a little bit about how your urinary symptoms have affected you?

2. What impact have they had on you?

This article is protected by copyright. All rights reserved. 
3. How have you been feeling about your urinary symptoms?

4. How confident are you that you will be able to get over these symptoms?

\section{Section 2: Questions about the continence programme}

The next questions are fairly general ones that help us to find out about your general impressions of the continence programme (the programme that is helping you train your bladder)

1. How has the programme helped you?

2. Imagine that a friend asked you to explain the programme. What would you tell them?

3. What are your expectations of the programme for yourself?

- What would you like to see happening by the time you leave hospital?

4. What do you think has been the best thing of taking part in the programme?

5. Has there been anything that you found difficult?

- Please explain.

- What did you do to overcome this?

- How did this help?

- What could we have done to help?

6. How have you found sticking to the programme?

7. Has it been hard to stick to the programme at times?

- Can you tell me a bit more about this?

8. What has helped you stick to the programme?

9. How are you feeling about continuing with the programme?

10. Have you spoken about the programme with family or friends?

- Who have you discussed it with?

- If you haven't discussed it, would you like to?

This article is protected by copyright. All rights reserved. 
11. If someone had a similar problem to you, would you suggest that they followed the programme?

- What advice would you give them?

- What would you do to encourage them?

12. Progress can be slow. If your symptoms are not better before you leave hospital, how would you feel about that?

- Would you carry on with the programme?

\section{Section 3: Questions about the information you were given}

I'd like to know about the information you were given. This was about how your bladder works and how a stroke can give you bladder problems. You learned about the programme and the reasons why it could be helpful. You also learned about how to improve emptying your bladder.

1. What was the most useful thing you learned from the education leaflet?

2. How was this useful?

3. We'd like to know what you think about the education leaflet.

a. What did you like about the education leaflet?

b. What did you not like about the education leaflet?

4. How could we make the education leaflet better?

- too much information, or too little, or about right?

- too difficult? too boring?

- couldn't remember it all?

5. How helpful was the section on how the bladder works?

a. How was it helpful

6. You were taught about distraction and relaxation strategies. How well did the nurses explain how they work?

This article is protected by copyright. All rights reserved. 
7. How helpful is it to know how things are supposed to work?

8. Is there anything else you would like in the education leaflet?

9. How well did the nurses answer any questions that you had?

\section{Section 4: Questions about the voiding programme/bladder training component}

These questions are about the bladder training part of the programme to help you get back to the pattern of voiding (passing urine / having wee / passing water /emptying bladder) before you had your stroke

1. What do you think of the programme?

- What was the biggest challenge?

- What was the easiest part?

2. Did you feel that the programme was designed especially for you?

3. Did you have enough support?

4. How well did you understand what you had to do?

- What could have been made clearer?

5. Was anything about the programme a surprise to you?

a. what was this?

6. Sometimes people following a programme have 'bad or not so good days' when it doesn't seem to be working.

- Have you had a day like this?

- What did you do?

- What helped you to get 'back on track'?

This article is protected by copyright. All rights reserved. 


\section{Section 5: Questions about the diary component}

These questions ask you to think about the diary you have been filling in about your voiding habits.

1. How did you find filling in the diary? (easy/difficult, interesting/boring/chore?)

2. When did you fill it in? (every few hours, every day, kept forgetting about it)

3. Did the diary help you become more aware of when you have a wee/when you pass urine/your voiding pattern?

- Tell me more.

- Has the diary shown you what helps and what doesn't help?

i. Please tell me more

4. How could we improve the diary?

\section{Section 6: Questions about the pelvic floor exercises}

These questions ask you to think about the pelvic floor exercises.

1. How easy was it to learn the exercises?

2. How easy is it for you to do the exercises?

3. Tell me about how you have fitted the exercises into your day.

- When do you do them?

- Does someone remind you?

- Does someone check you have done them?

4. Do you always do the exercises twice a day?

- If not, what stops you?

5. How much have the exercises helped?

- when did you first notice a difference?

- what has changed?

This article is protected by copyright. All rights reserved. 


\section{Section 7: Questions about the outcome criteria}

These questions ask you about the ways the researchers can find out if the programme is working.

1. How has the programme helped your problems with your bladder?

2. We hope that the programme will stop patients being incontinent, or reduce the number of times that they are incontinent.

Are there any other things that the researchers need to know?

- you might not feel the need to go to the toilet so often

- you can 'hold on' for longer

- you might like home support (visit from a specialist)

- you might like a telephone number for advice and support.

- You might want advice about coping with your bladder problems when you go out

- You might want to know about other things that can help you manage with your bladder problems

\section{Section 8: Final question(s)}

If they are still having problems:

1. How confident are you that you can stick to the programme over the next 4 weeks?

- Do you have any anxieties about it?

- What kind of things will help you to stick to the programme?

- What kind of things may stop you sticking to the programme?

These questions help to round-off the interview

1. What is the most important thing we should know about your experience of the programme?

2. What could make the programme better for you?

3. Is there anything else you would like to tell us?

\section{Thank you so much for taking part; it's been very interesting talking to you.}

This article is protected by copyright. All rights reserved. 